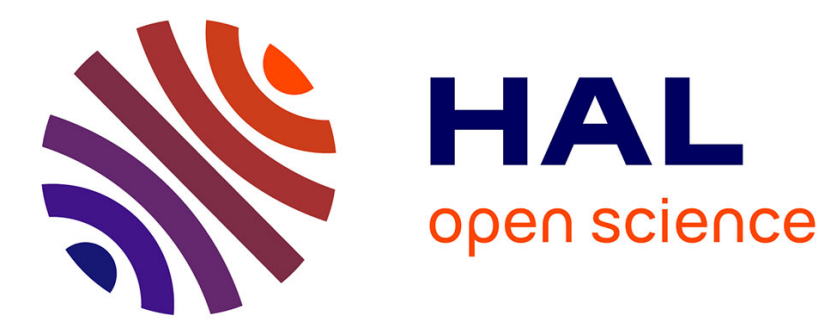

\title{
Bailout policy in a globalized economy
}

Nelly Exbrayat, Thierry Madiès, Stéphane Riou

\section{To cite this version:}

Nelly Exbrayat, Thierry Madiès, Stéphane Riou. Bailout policy in a globalized economy. 2014. halshs-00925006

\section{HAL Id: halshs-00925006 https://shs.hal.science/halshs-00925006}

Preprint submitted on 7 Jan 2014

HAL is a multi-disciplinary open access archive for the deposit and dissemination of scientific research documents, whether they are published or not. The documents may come from teaching and research institutions in France or abroad, or from public or private research centers.
L'archive ouverte pluridisciplinaire HAL, est destinée au dépôt et à la diffusion de documents scientifiques de niveau recherche, publiés ou non, émanant des établissements d'enseignement et de recherche français ou étrangers, des laboratoires publics ou privés. 


\section{Bailout policy in a globalized economy}

Nelly Exbrayat, Thierry Madiès, Stéphane Riou 


\section{GATE Groupe d'Analyse et de Théorie Économique Lyon-St Étienne}

93, chemin des Mouilles 69130 Ecully - France

Tel. +33(0)4 72866060

Fax $+33(0) 472866090$

6, rue Basse des Rives 42023 Saint-Etienne cedex 02 - France

Tel. +33 (0)4 77421960

Fax. +33 (0)4 77421950

Messagerie électronique / Email : gate@gate.cnrs.fr

Téléchargement / Download : http://www.gate.cnrs.fr - Publications / Working Papers 


\title{
Bailout policy in a globalized economy*
}

\author{
Nelly Exbrayat† Thierry Madiès ${ }^{\ddagger} a n d$ Stéphane Riou ${ }^{\S}$
}

\begin{abstract}
This paper explores how trade integration influences the decision by national governments to bailout manufacturing firms. We develop a 2-country model of generalized oligopoly with heterogenous firms and trade costs. High-cost firms are eligible for a bailout while low-cost firms are profitable. Our results show that trade liberalization influences both political benefits of a bailout and its relative cost as compared to a laissez-faire policy. If the fall in trade cost is so large that it allows high-cost firms to become exporters, governments might move away from a bailout policy to a laissez-faire policy. In contrast, a marginal decline in trade costs that does not affect the export status of high-cost firms, always makes governments more prone to adopt a bailout decision.

Keywords: soft-budget constraint; tax competition; heterogenous firms; trade cost; location.
\end{abstract}

JEL classification: F12; F15; D21; H25.

${ }^{*}$ We are grateful to participants of $3^{r d}$ SEBA GATE workhop (Chengde), at $59^{\text {th }}$ annual RSAI conference (Ottawa), at $4^{\text {th }}$ UECE Meetings on Game theory and application (Lisbon), at GATE workshop on Public Policies and Spatial Economy (Lyon and Saint-Etienne), at CESAER seminar in Dijon, and to Jacques-François Thisse, Frédéric Robert-Nicoud, Cécile Detang Dessendre, Maire-Laure Breuillé and Simon Lapointe for helpful comments and suggestions.

${ }^{\dagger}$ Université de Lyon, Lyon, F-69007, France ; CNRS, GATE Lyon Saint-Etienne, Ecully, F-69130, France ; Université Jean Monnet, Saint-Etienne, F-42000, France.

$\ddagger$ University of Fribourg, Faculté des sciences économiques et sociales, boulevard de Perolles, 90, 1700 Fribourg (Switzerland).

§Université de Lyon, Lyon, F-69007, France ; CNRS, GATE Lyon Saint-Etienne, Ecully, F-69130, France ; Université Jean Monnet, Saint-Etienne, F-42000, France. 


\section{Introduction}

A firm - or any institution - is faced with a soft-budget constraint if it expects to be bailed out in case of financial trouble. This creates a moral hazard problem as the expectation of a bailout can erode managers' effort and thereby encourage failure. ${ }^{1}$ Originally developed by Kornai (1979, 1986), the concept of 'soft-budget constraint' (hereafter SBC) was first designed to describe the behavior of governments in centrally planned and transition economies. ${ }^{2}$ However, the recent crisis period resulted in a widespread policy of industry bailout in most of the developed countries, in addition to tremendous rescue plans in the financial and banking sector. The most emblematic example is certainly the federal bailout for America's Big Three automobile companies in 2009, but many rescue plans have been decided in other countries and industrial sectors over the past decades. ${ }^{3}$ These examples corroborate the claim by Kornai, Maskin and Roland (2003, p. 56) that "the effects of the SBC syndrome are clearly perceptible in the traditionally capitalist part of the world as well". One reason is that some determinants like the political desirability of a bailout are not proper to a particular economic or political system (see. Robinson and Torvik, 2009). Politicians may be politically motivated to grant subsidies to companies in financial trouble to save jobs. In addition, policy-makers may be concerned by the 'too big to fail' argument when failures cause negative spillovers on the rest of the economy.

The soft budget constraint phenomenon has been studied mainly in a closed economy framework (see. Kornai, Maskin and Roland, 2003 ). This is clearly a limit of the literature because corporate bailouts in well-established market economies have been taking place over the two last decades in a new context of globalization characterized by both increasing capital mobility and trade openness. Our paper aims at analyzing how corporate bail-out decisions can be shaped by these two driving forces of globalization.

A vast empirical literature shows that globalization disciplines governments. It could incite them to reduce waste and inefficient policies in order to provide a more business-

\footnotetext{
${ }^{1}$ For example, firms might under-invest in order to become unprofitable and obtain subsidies (Segal, 1998).

${ }^{2}$ Kornai, Maskin and Roland (2003) provide a detailed review of the soft-budget constraint literature.

${ }^{3}$ Even in the European Union where state aids are forbidden as soon as they threaten to distort competition by favouring certain undertakings or the production of certain goods (article 107 of the TFEU), governments can bailout firms through the so-called 'State aids for rescuing and restructuring firms in difficulty'. According to Chindooroy, Muller and Notaro (2007), 86 rescue and restructuring State aid cases were approved by the Commission between 1995 and 2003, in various sectors and mostly in western countries. For additionnal examples of bailouts in developed countries over the period 1980-2008, see Kornai (2009).
} 
friendly environment (see. Rodrik, 1997, Schulze and Ursprung, 1999). ${ }^{4}$ One could therefore expect that globalization moderates the use of corporate bailouts. Yet, few theoretical contributions explore this issue. An exception is the contribution by Alexeev and Jang (2010), that places Segal's (1998) SBC model within Melitz (2003) framework characterized by trade and heterogeneous firms. The main SBC-induced inefficiency arises from the fact that some firms subject to a bailout exert a sub-optimal effort. Trade liberalization reduces this inefficiency and the number of firms eligible for a bailout by raising the average level of effort. However, this contribution does not specifically address whether or not trade costs also influence bailout decisions. In addition, they abstract from the effects of firm mobility. Another important contribution by Qian and Roland (1998) explores the determinants of the SBC in the context of federal economies. They show that by inducing fiscal competition among local governments, "factor mobility increases the opportunity costs of bailout and then serves as a commitment device" (Qian and Roland, 1998, p. 1143). In sum, while the latter contribution provides a first insight regarding the impact of capital mobility on corporate bailouts, the former explores how trade liberalization influences the number of firms eligible for such bailouts. Our contribution goes further by investigating the issue of corporate bailouts in economies characterized by both capital mobility and international trade.

To do so, we develop a trade and location model with two symmetric countries and heterogeneous firms. Some firms are domestic and immobile, while others are mobile and owned by foreign investors residing in a third country. They all compete on the same oligopolistic market. Importantly, foreign firms are always profitable because they are run by market-oriented managers. In contrast, domestic ones are run by politically-connected managers and might be eligible for a bailout. Our model thus captures two important features. Firstly, the existence of politically-connected firms and their higher probability to be rescued by the government is documented by Faccio, Masulis and McConnell (2006) for a large sample of (mostly) developed countries. ${ }^{5}$ Secondly, capital invested in these firms is often partially state-owned and might therefore be less footloose than capital invested in competing multinational firms. Finally, our model exhibits various interactions embedded in a sequential game à la Qian and Roland (1998). In a first stage, politicallyconnected managers choose to exert either a high or low effort. A high effort can be viewed as restructuring the firm. In contrast, a low effort results in financial difficulties for the

\footnotetext{
${ }^{4}$ See. Cai and Tresman (2005) for an opposite view.

${ }^{5}$ Firms are defined as politically-connected when at least one of its large shareholders or one of its top officers is a member of parliament, a minister, or is closely related to a top politician or party.
} 
firm so that it cannot survive without a bailout. In the latter case, the government has to decide in a second stage whether to rescue the firm through a full exoneration of the corporate tax (bailout policy) or to let it go bankrupt (laissez-faire policy). Importantly, we retain a 'too-big to fail' argument by assuming that political benefits from a bailout accruing to the government are proportional to the size of firms, or equivalently, to their total labor force. In a third stage, governments non-cooperatively levy a lump-sum tax on all profitable firms. The two last stages describe the location choice of foreign investors and the market outcome.

Our model suggests a non-univocal relationship between trade liberalization and the decisions to bailout, because trade costs can influence the relative cost of a bailout and its political benefits in various ways.

Firstly, the trade cost level influences political benefits through its impact on the export status of firm, and, in fine, on their size. When trade costs are high, a firm eligible for a bailout is not competitive enough to export and bilateral trade is exclusively driven by foreign firms set up in each country (trade regime 1). This is only once trade costs reach a lower threshold value that the former begins to export as well (trade regime 2). Depending on whether trade regime 1 or 2 prevails, the impact of trade liberalization on the size of firms eligible for a bailout goes in opposite directions: it increases with a fall in trade costs when they are exporter whereas it shrinks when they only serve the domestic market because of fiercer competition. As a result, trade liberalization reduces (resp. increases) political benefits from a bailout under trade regime 1 (resp. trade regime 2).

Secondly, a bailout also distorts the market outcome by sustaining domestic competitors. As argued by Slaughter (2008), the evaluation of the cost of a bailout policy must account for the way foreign and footloose competitors set up in the country may react to such a distortion. In our model, a bailout policy maintains a higher number of domestic competitors on the market, so that mobile firms are more responsive to a rise in taxation. This often leads governments to set lower taxes and extract less tax revenues if they rescue firms than if they adopt a laissez-faire policy. Importantly, this relative cost of a bailout - as compared to a laissez-faire policy - is bigger when firms eligible for a bailout become exporters, but it diminishes with the gradual decline in trade costs whatever the trade regime.

By combining these effects, we obtain our main finding that can be summarized as follows. When trade regime 1 prevails, the gradual decline in trade costs makes the bailout policy more and more likely. Indeed, the decrease in the relative cost of a bailout does 
more than compensate the fall in its political benefits. When the two countries switch from trade regime 1 to trade regime 2, the laissez-faire policy becomes more likely because of the sudden rise in the relative cost of the bailout. Lastly, as trade integration deepens further, incentives to bail out domestic firms unambiguously grow because the relative cost of a bailout shrinks while its political benefits increase.

The remainder of the paper is organized as follows. The model is described in section 2. In the following sections, we solve the sequential game by backward induction. Section 3 is devoted to the presentation of production and consumption outcomes for a given spatial distribution of mobile firms and for given policy decisions. This allows us to identify the range of trade cost values corresponding to each trade regime and to analyze how competition effects are influenced by the decision to rescue firms or not. In section 4 , we describe the location equilibrium and the tax competition outcome in our benchmark case (trade regime 2), for a given policy decision regarding firms eligible for a bailout. In section 5 , we analyze the determinants of the bailout decision by governments across each trade regime and the last section concludes.

\section{The Model}

The economy consists of two countries, labelled $i=A, B$, equally populated by $L_{A}=$ $L_{B}=L / 2$ individuals. ${ }^{6}$ There are two factors of production - labor and capital - and two sectors, which are always active in the two countries. Each individual in country $i$ provides one unit of labor and is endowed with an equal share of capital. These factors are employed in the country of residence of the individual. The stock of domestic capital is completed by foreign capital owned by individuals living outside the economy. Contrary to domestic capital, foreign capital is mobile and can be invested either in country $A$ or $B$. While labor can either be employed in a manufacturing sector ( $M$ sector) or a traditional sector ( $T$ sector), capital is only needed in the former.

The $M$ sector is characterized by $k$ oligopolistic firms producing a homogenous good $x$. Exporting this good involves a per-unit cost of $\tau$ units of numeraire. These firms enjoy increasing returns to scale. A fixed quantity of capital that we normalize to unity and one local manager are always required to start production. Moreover, they may differ in two respects. Firstly, firms relying on domestic capital are immobile whereas those using foreign capital are mobile. ${ }^{7}$ Secondly, depending on the origin of the capital

\footnotetext{
${ }^{6}$ Countries are assumed to be identical in all respects in order to control for any comparative advantage.

${ }^{7}$ The wave of privatization that began in developped countries in the late 1970s is not completely
} 
of the firm they run, the managers' profile is not the same. Managers of foreign firms are 'market-oriented': they always exert a high effort resulting in a low marginal cost so that their firm is profitable. In contrast, domestic firms are run by managers that are 'connected politically' with the government. These managers know that their firm can potentially be bailed-out in case of financial trouble. Therefore, they can choose among two levels of effort: a low effort results in a high marginal cost of production so that the firm becomes eligible for a bailout and survive if and only if this bailout is implemented, whereas a high effort leads to the same marginal cost as foreign firms and guarantees their profitability without any governmental support. To summarize, domestic and immobile firms run by politically-connected managers compete with foreign and mobile firms run by market-oriented managers on the same oligopolistic market.

In the $T$ sector, firms produce the numeraire commodity $z$ under perfect competition using workers only. Specifically, one unit of labour is required to produce one unit of output, so that wages are equalized to one in this sector.

Note that our modelling of the labor market shares many common assumptions with footloose capital models (see, Henderson and Thisse, 2004) : labor supply is inelastic, immobile across countries but mobile across sectors and the numéraire sector is always active in both countries. We make two additional assumptions. For convenience and to avoid the modelling of two distinct labor markets, managers and production workers are perfect substitutes. It allows all wages to be equalized to unity as in footloose capital models. Thus, our approach voluntarily abstracts from wage considerations in order to focus on the role of employment for the bailout decision. Secondly, we ensure that whatever the bailout decision and the resulting market outcome, the total labor supply is high enough to make production possible. These two assumptions are explicitly described in the Appendix A.

In the following, we describe in more detail the different types of manufacturing firms (section 2.1) and the sequence of interactions between firms and governments (section $2.2)$.

achieved (see Bortoletti and Faccio, 2009). As a result, in many countries, capital invested in former state-owned firms is still mostly owned by the government and less footloose than capital invested in competing multinational firms. With our modelling strategy regarding the manufacturing sector, we try to build a model that fits this context. 


\subsection{Manufacturing firms and the government}

We set the total number of domestic firms to 4 ( 2 in each country). ${ }^{8}$ Their managers are strongly linked to the government. Therefore, their behavior depends on their expectations of financial support they might receive from policy-makers. Specifically, politicallyconnected managers can choose among two alternatives. The first one consists in making a high effort which can be interpreted as 'strongly restructuring'. In this case, the firm enjoys a zero marginal cost, is profitable and thus subject to lump-sum taxation by the government. Alternatively, the manager can exert a low effort. In this case, the marginal cost is positive and normalized to one labor unit. These high cost firms are considered as eligible for a bailout. We model this bailout in a simple way by assuming that it takes the form of a full tax exemption, a common mean to rescue firms (see Kornai, Maskin and Roland, 2003, and Shleifer and Treisman, 2000). ${ }^{9}$ Without such a tax exemption, high cost firms go bankrupt.

Because of their position, politically-connected managers also enjoy non-monetary benefits. By non-monetary benefits, we consider all advantages resulting from their relationship with some members of the government, which gives them some political influence. These benefits are assumed to be higher, the larger the number of workers employed in the firm. Specifically, each politically-connected managers receives (net of effort) benefits equal to $E$ times the number of workers employed. Let $\ell$ denote the total labor force (including the manager) in a high-cost firm. Thus, a politically-connected manager receives $E \cdot \ell$ if he exerts a low effort, and $E$ if he exerts a high effort since in this case $\ell=1$. This is in line with Qian and Roland (1998) who assume that benefits are higher when managers exert a low effort and anticipate a bailout, in order to ensure that a bailout decision can arise at the equilibrium. Moreover, this modeling strategy is a simple way to render the bailout decision endogenous to the number of jobs in the manufacturing sector (see, section 5). Specifically, our model captures the 'too big to fail' argument that contributes to explain why governments often choose to rescue the largest firms.

The remaining $k-4$ foreign firms are run by market-oriented managers. They feel entirely responsible for the survival of the firm and thus always exert a high effort inducing

\footnotetext{
${ }^{8}$ We fix the number of politically-connected firms in each country to 2 in order to convey our message in a simple way and to simplify the algebra. However, we could develop our analysis for any given number of domestic firms without changing our qualitative results.

${ }^{9}$ Tax exemptions fall in one of the categories of means of rescue listed by Kornai, Maskin and roland (2003). This category consists of fiscal means, that can either take the form of subsidies or tax concessions. The two other categories are credit and the various indirect methods of support.
} 
a zero marginal cost. As these firms are profitable, they are subject to lump-sum taxation by the government of the hosting country. Recalling that capital invested in these firms is mobile, their capital owners will thus compare the net profits across the two countries and decide to invest where the net-return to capital is the highest.

\subsection{Sequence of events}

Our model contains various forms of interactions that are embedded in the following sequential game (see Figure 1):

Stage 0 [Effort choice of politically connected managers]. Politically connected managers choose a high or low level of effort given the value of individual non-monetary benefits, and anticipating the outcome of all subsequent stages.

Stage 1 [Bailout or laissez-faire policy]. If a low effort is chosen at stage 0, governments decide whether to rescue high-cost firms through a full tax exemption (bailout policy), or to let them go bankrupt (laissez-faire policy). When doing so, they perfectly anticipate the tax competition outcome, the location of foreign firms and the resulting market outcome.

Stage 2 [Taxation of firms]. Governments simultaneously and non-cooperatively choose the level of lump-sum tax levied on all low-cost firms, given decisions taken at stages 0 and 1. At this stage, governments perfectly anticipate the location of foreign firms as well as the market outcome.

Stage 3 [Location of foreign firms]. Foreign capital owners decide whether to invest in country $A$ or $B$ given the observed levels of taxation in each country and anticipating the market outcome.

Stage 4 [Production and consumption]. Surviving firms make their output choices and consumption takes place. The remaining firms go bankrupt.

As we can see from Figure 1, the sequential game consists of 4 or 5 stages depending on the effort choice made by politically-connected managers. Importantly, decisions taken at stages 0 and 1 will lead to three potential decision paths denoted by $\theta \in\{H, \bar{H}, S\}$, where $H$ and $\bar{H}$ refer to a laissez-faire policy (or hard-budget constraint) and $S$ stands for the bailout scenario (or soft-budget constraint). Among these three potential outcomes, only decision paths $H$ and $S$ in solid lines are perfect subgame equilibrium candidates. Let us first assume that managers perfectly anticipate a bailout. Then, as $E \cdot \ell>E$, they will prefer to exert a low level of effort because they will enjoy higher non-monetary benefits than if they exert a high effort. Let us now consider that they anticipate a laissez- 


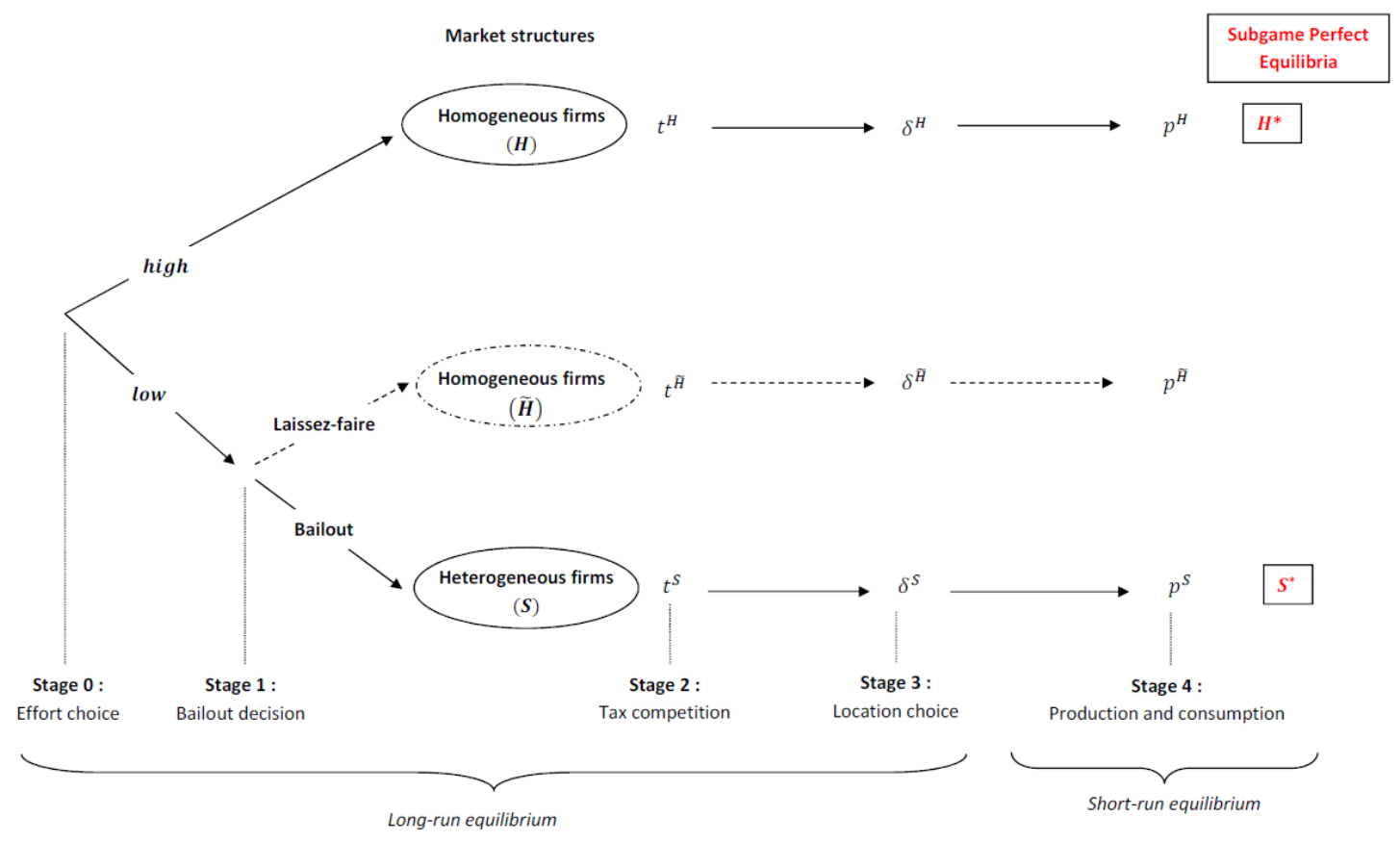

Figure 1: Structure of the game

faire policy. Then, it is always optimal for politically-connected managers to exert a high level of effort as it yields a positive non-monetary benefit $E$. Otherwise, the firm goes bankrupt, managers lose their job and thus receive no benefit. The decision path $\bar{H}$ in dotted lines is therefore off the equilibrium path. Nevertheless, we need to evaluate the outcome along this decision path in order to determine which one of the decision paths $S$ or $H$ will be the subgame perfect equilibrium of the game (see section 5 ).

As this is well known, the solution to such a sequential game is given by a subgame perfect Nash equilibrium that we obtain by backward induction beginning with the last stage of the game. ${ }^{10}$ In the following section, we analyze how production and consumption choices made in the last stage are influenced by the bailout vs. laissez-faire decision.

\section{Short-run equilibrium (stage 4)}

In this section, we present the outcome at the last stage of the game. We call it the shortrun equilibrium as it describes the production and consumption outcomes for a given spatial distribution of foreign firms.

\footnotetext{
${ }^{10}$ Because of the symmetry of our model, this equilibrium outcome is the same in each country.
} 


\subsection{Consumption}

Individuals share identical preferences given by a quasi-linear utility function:

$$
u_{i}^{\theta}=a x_{i}^{\theta}-\frac{1}{2}\left(x_{i}^{\theta}\right)^{2}+z_{i}^{\theta} \quad \forall i \in\{A, B\} \text { and } \theta \in\{H, \bar{H}, S\}
$$

where $x_{i}$ is the consumption of the manufacturing good, $z_{i}$ the consumption of the numeraire and $\bar{z}$ is the individual endowment in the numeraire.

Let $T_{i}$ stand for tax revenues from all low-cost firms that are redistributed equally and in a lump-sum fashion to the consumers in each country. The budget constraint for a representative consumer in each country $i$ is then:

$$
\begin{aligned}
1+\bar{z}+\frac{T_{i}^{\theta}}{L / 2}+\frac{2 \rho_{i}^{l, \theta}}{L / 2} & =z_{i}^{\theta}+p_{i}^{\theta} x_{i}^{\theta} \text { if } \theta \in\{H\} \\
1+\bar{z}+\frac{T_{i}^{\theta}}{L / 2} & =z_{i}^{\theta}+p_{i}^{\theta} x_{i}^{\theta} \text { if } \theta \in\{\bar{H}, S\}
\end{aligned}
$$

where $p_{i}$ is the price of the good produced in the M-sector and $\rho_{i}^{l, \theta}$ is the after-tax return to capital invested in domestic firms that are low-cost. Importantly, individuals receive no income from capital when managers of domestic firms exert a low effort. Indeed, in such a case, two scenarios can occur. If governments adopt a laissez-faire policy $(\theta=\bar{H})$, the decision to produce would induce a negative net return to capital. Thus, firms go bankrupt and individuals earn no capital income. If governments instead decide to rescue these firms through a tax exemption $(\theta=S)$, we assume that the bailout just allows firms to survive. ${ }^{11}$ In our model, it means that the gross return to capital invested in high-cost firms is equal to zero.

Utility maximization leads to the individual inverse demand function with respect to the manufacturing good

$$
p_{i}^{\theta}=a-x_{i}^{\theta}
$$

Aggregating the demand over all consumers yields market demand curves for each country $i$ in the oligopolistic industry :

$$
X_{i}^{\theta}=\frac{L}{2}\left(a-p_{i}^{\theta}\right)
$$

\footnotetext{
${ }^{11}$ For the sake of simplicity, we do not explicitly model their profitability condition but the bailout can be viewed as necessary for the repayment of loans.
} 


\subsection{Production}

We assume manufacturing firms compete in quantities. ${ }^{12}$ Before describing their output choices, two comments are in order.

Firstly, we point out that both the effort choice of managers and the bailing-out decision of governments affect the number of competitors on the market, and thus the toughness of competition, as shown in Table 1.

\begin{tabular}{|c|c|c|c|}
\hline & $\boldsymbol{\theta}=\boldsymbol{H}$ & $\boldsymbol{\theta}=\widetilde{\boldsymbol{H}}$ & $\boldsymbol{\theta}=\boldsymbol{S}$ \\
\hline Surviving firms & $k$ low cost firms & $k-4$ low cost firms & $\left\{\begin{array}{c}k-4 \text { low cost firms } \\
4 \text { high cost firms }\end{array}\right.$ \\
\hline Dying firms & 0 & 4 high cost firms & 0 \\
\hline
\end{tabular}

Table 1: Number and type of firms

The first path occurs when politically-connected managers decide to exert a high effort given their anticipation of a laissez-faire policy $(\theta=H)$. As a result, there will be oligopolistic competition among $k$ low-cost firms, among which 4 domestic firms and $k-4$ foreign firms. Along the second path, politically-connected managers exert a low effort while the government adopts a laissez-faire policy $(\theta=\bar{H})$. This implies oligopolistic competition among $k-4$ foreign low-cost firms. The last path describes the bailout policy $(\theta=S)$, and gives rise to oligopolistic competition among $k$ heterogenous firms: 4 domestic high-cost firms, and $k-4$ foreign low-cost firms.

Secondly, the level of trade liberalization shapes output decisions. Indeed, recall that the cost incurred by a firm for exporting each unit of the manufacturing good is equal to $\tau$ units of the numeraire. ${ }^{13}$ Because of these trade costs, firms are able to segment their markets by choosing the quantities to sell on the domestic and the foreign market independently.

We are now equipped to describe the product market outcome. Let $x_{i i}^{c, \theta}$ and $x_{i j}^{c, \theta}$ denote the output choices made by a firm located in country $i$, which depend on the marginal cost, low or high $(c \in\{l, h\})$ as well as the number of surviving firms through $\theta \in\{H, \bar{H}, S\}$. Before-tax profits made by low-cost and high-cost surviving firms are

\footnotetext{
${ }^{12}$ The same modeling strategy is used, among others, by Gaigné and Wooton (2011), Haufler and Wooton (2010), and Thisse (2010).

${ }^{13}$ This captures all frictions making bilateral trade costly including transport costs or administrative barriers to the free mobility of goods between countries.
} 
described by equations 3 and 4 respectively:

$$
\begin{aligned}
\pi_{i}^{l, \theta} & =p_{i}^{\theta} x_{i i}^{l, \theta}+\left(p_{j}^{\theta}-\tau\right) x_{i j}^{l, \theta}-1-r_{i}^{l, \theta} \text { with } \theta \in\{H, \bar{H}, S\} \\
\pi_{i}^{h, S} & =\left(p_{i}^{S}-1\right) x_{i i}^{h, S}+\left(p_{j}^{S}-1-\tau\right) x_{i j}^{h, S}-1-r_{i}^{h, S}
\end{aligned}
$$

where $r_{i}^{l, \theta}$ is the gross return to capital. In the long run, this return to capital absorbs all operating profits.

Maximizing (3) and (4) with respect to quantities, we get the following output levels for a low-cost firm:

$$
x_{i i}^{l, \theta}=\frac{L}{2} p_{i}^{\theta} \text { and } x_{i j}^{l, \theta}=\frac{L}{2}\left(p_{j}^{\theta}-\tau\right) \text { with } \theta \in\{H, \bar{H}, S\}
$$

and for a surviving high-cost firm:

$$
x_{i i}^{h, S}=\frac{L}{2}\left(p_{i}^{S}-1\right) \text { and } x_{i j}^{h, S}=\frac{L}{2}\left(p_{j}^{S}-1-\tau\right)
$$

Equilibrium prices are obtained by inserting the equilibrium output choices (5) and (6) in the market clearing conditions. Let $\delta_{i}^{\theta}$ denotes the share of foreign firms located in country $i$ under $\theta$, then equilibrium prices are as follows:

$$
\begin{gathered}
p_{i}^{\bar{H}} \equiv \frac{a+\tau\left[\delta_{j}^{\bar{H}}(k-4)\right]}{k-3} \\
p_{i}^{H} \equiv \frac{a+\tau\left[\delta_{j}^{H}(k-4)+2\right]}{k+1} \\
p_{i}^{S} \equiv \frac{a+\tau\left[\delta_{j}^{S}(k-4)+2\right]+4}{k+1}
\end{gathered}
$$

Three comments are in order. Firstly, observe that the toughness of competition is captured by the denominator of each expression (equal to the number of surviving firms plus one). Secondly, $p_{i}^{S}>p_{i}^{H}$ at the symmetric location equilibrium where $\delta_{j}=1 / 2$. Indeed, the average marginal costs is higher under bailout policy because high-cost firms survive. Moreover $p_{i}^{\bar{H}}>p_{i}^{H}$ at $\delta_{j}=1 / 2$, because the number of competitors is lower when governments let high-cost firms go brankrupt. Finally, as the number of surviving firms resulting from $\bar{H}$ differs from the one arising from $S$ and $H$, the price responsiveness to the spatial distribution of foreign firms varies accordingly. Specifically, we verify that $d p_{i}^{\bar{H}} / d \delta_{j}>d p_{i}^{H} / d \delta_{j}=d p_{i}^{S} / d \delta_{j}$.

We now determine the trade feasibility conditions ensuring that exporting is always profitable for firms along the two equilibrium paths $\theta \in\{H, S\}$. We obtain the following condition for low-cost firms located in $i$ :

$$
x_{i j}^{l, H}>0 \quad \forall \tau<\tau^{H}=2 \frac{a}{k+2}
$$


and the same condition applies for firms located in country $j .{ }^{14}$ The trade feasibility condition ensuring that high-cost firms export is given by:

$$
x_{i j}^{h, S}>0 \quad \forall \tau<\tau^{S}=2 \frac{a-k+3}{k+2}
$$

with $\tau^{S}>0$ for all $a>a_{\text {min }} \equiv k-3 .^{15}$

Clearly, these two threshold values can be ranked in the following manner: ${ }^{16}$

$$
\tau^{S}<\tau^{H}
$$

Thus, the level of trade costs affects the distribution of surviving firms on the export market as stated by Lemma 1 .

Lemma 1 Let us define trade regime 1 by $\tau \in\left(\tau^{S}, \tau^{H}\right)$ and trade regime 2 by $\tau \in\left(0, \tau^{S}\right)$. Then:

- Under trade regime 1, low-cost firms are exporters while high-cost firms only serve their domestic market;

- Under trade regime 2, all firms serve both markets.

Starting from the highest possible level of prohibitive trade cost (that is, $\tau^{H}$ ), trade liberalization will first allow low-cost firms to export and it is only once trade costs reach a lower threshold value (that is, $\tau^{S}$ ) that high-cost firms rescued by the government will also begin to export. ${ }^{17}$ Therefore, we explore the effects of liberalization over a wider range of trade cost values than in Okubo, Picard and Thisse (2010), who focus on the spatial selection of firms induced by trade liberalization under trade regime $2^{18}$.

\footnotetext{
${ }^{14}$ The model being symmetric, all trade feasibility conditions are evaluated at $\delta_{i}^{\theta}=\delta_{j}^{\theta}=1 / 2$ and apply also to firms located in country $j$.

${ }^{15}$ Hereafter, this condition is considered as fulfilled. The demand parameter $a$ is high enough to make the export by bailed-out firms dependent on the trade cost level.

${ }^{16}$ The condition ensuring that low-cost firms are profitable on the export market writes $\tau<$ $2 a /(k-2) \equiv \tau^{\bar{H}}$. This is the less restrictive condition as we verify that $\tau^{\bar{H}}$ is always higher than $\tau^{S}$ and $\tau^{H}$.

${ }^{17}$ Note also that $p_{i}^{S}<p_{i}^{\tilde{H}}$ when $\tau<\tau^{S}$.

${ }^{18}$ In their paper, all firms are mobile and export whatever their cost level and the market size differs across countries.
} 


\section{Tax Policy and Location under Trade Regime 2: Laissez-faire vs. Bailout}

In the following subsections, we consider trade regime 2 as a benchmark case to solve both the location and the tax competition equilibria. This will allow us to compare the impact of a laissez-faire versus bailout policy on the location of foreign firms (section 4.1) and on the tax competition outcome (section 4.2). Trade regime 1 will be analyzed in section 5 , where we solve the stages 1 and 0 , and study the effect of trade liberalization on the bailout decision for both trade regimes.

\subsection{Location equilibrium (stage 3 )}

In the long run, the equilibrium rental rate to foreign capital in each country is determined by a bidding process, which ends when no foreign firm can earn a strictly positive profit at the equilibrium market price. Therefore, before taxation, the equilibrium rental rate to capital writes:

$$
\begin{aligned}
& r_{i}^{l, \theta}=p_{i}^{\theta} x_{i i}^{l, \theta}+\left(p_{j}^{\theta}-\tau\right) x_{i j}^{l, \theta}-1 \text { with } \theta \in\{H, \bar{H}, S\} \\
& r_{i}^{h, S}=\left(p_{i}^{S}-1\right) x_{i i}^{h, S}+\left(p_{j}^{S}-1-\tau\right) x_{i j}^{h, S}-1
\end{aligned}
$$

As governments non-cooperatively impose a lump-sum tax $t_{i}^{\theta}$ on low-cost firms set up within their respective jurisdictions, the after-tax return to capital invested in low-cost firms in country $i$ is given by:

$$
\rho_{i}^{l, \theta}=r_{i}^{l, \theta}-t_{i}^{\theta}
$$

Owners of capital invested in foreign firms decide to invest in the most profitable country. Therefore, the location of foreign firms is governed by the spatial difference in

net returns to capital $\Delta^{l, \theta}=\left(r_{A}^{l, \theta}-t_{A}^{\theta}\right)-\left(r_{B}^{l, \theta}-t_{B}^{\theta}\right)$. After inserting equilibrium prices and quantities in (10), we obtain:

$$
\Delta^{l, \theta}=\left\{\begin{array}{l}
t_{B}-t_{A}-L \tau^{2} \frac{\left(2 \delta_{A}^{\theta}-1\right)(k-4)}{k+1} \text { for } \theta \in\{H, S\} \\
t_{B}-t_{A}-L \tau^{2} \frac{\left(2 \delta_{A}^{\theta}-1\right)(k-4)}{k-3} \text { for } \theta=\bar{H}
\end{array}\right.
$$

The location equilibrium for each $\theta$ can be defined as the share of foreign firms located in country $A\left(\delta_{A}^{\theta}\right)$ such that $\Delta^{\theta}=0$, that is: 


$$
\begin{gathered}
\delta_{A}^{\bar{H}}=\frac{1}{2}-\frac{1}{2} \frac{k-3}{L \tau^{2}(k-4)}\left(t_{A}-t_{B}\right) \\
\delta_{A}^{H}=\delta_{A}^{S}=\frac{1}{2}-\frac{1}{2} \frac{k+1}{L \tau^{2}(k-4)}\left(t_{A}-t_{B}\right)
\end{gathered}
$$

The above location equilibria are the result of two forces.

The first one is standard and depicts a pro-competitive effect. When a country hosts new firms, incumbent firms face more competitors in their domestic market and fewer in the other one. Thus, the domestic price falls while it rises in the other market (see equations 7, 8 and 9). Because domestic sales generate more revenues in the presence of trade costs, this effect acts as a dispersion force. Importantly, this effect is proportional to the number of surviving firms and is captured by the terms $k-3$ and $k+1$. This number being the same under $\theta \in(H, S)$, the location equilibrium is identical.

The second force results from the impact of the tax wedge on the location choice. ${ }^{19} \mathrm{~A}$ unilateral rise in corporate taxation in country $i$ leads to an outflow of capital $\left(d \delta_{i}^{\theta} / d t_{i}^{\theta}<\right.$ $0)$. Moreover, as competition is fiercer when $\theta \in\{H, S\}$, firms are more responsive to tax variations and the tax base erosion effect is stronger. We also verify that the tax base elasticity (defined as $\varepsilon_{i}^{\theta}=-\partial \delta_{i}^{\theta} / \partial t_{i}^{\theta} \cdot t_{i}^{\theta} / \delta_{i}^{\theta}$ ) increases when trade costs fall because prices become less and less responsive to the spatial distribution of firms. In other terms, gradual trade integration weakens the pro-competitive effect which increases the weight of taxes in the capital location choice.

\subsection{Tax competition (stage 2)}

Governments decide non-cooperatively and independently upon their tax policy. We assume that their objective is to maximize:

$$
W_{i}^{\theta}=\mathbf{R}_{i}^{\theta}+\varphi \mathbf{E}_{i}^{\theta}
$$

where $\mathbf{R}_{i}^{\theta}$ denotes the overall net income of residents. $\mathbf{E}_{i}^{\theta}$ stands for total non-monetary benefits received by politically-connected managers and $\varphi>0$ is a parameter aimed at capturing how much the government cares about them. Interestingly, as $\mathbf{E}_{i}^{\theta}$ incorporates the labor force employed by domestic firms in the manufacturing sector, $\varphi$ can also be viewed as the extent to which governments care about those jobs.

\footnotetext{
${ }^{19}$ Despite their lump-sum form, taxes distort the investment choice through the spatial distribution of foreign firms.
} 
Each one of the component of this objective function varies across the decision paths $\theta$. The overall income of residents is given by:

$$
\begin{aligned}
\mathbf{R}_{i}^{H} & =\frac{L}{2}(1+\bar{z})+t_{i}^{H}\left[(k-4) \delta_{i}^{H}+2\right]+2 \rho_{i}^{l, H} \\
\mathbf{R}_{i}^{\theta} & =\frac{L}{2}(1+\bar{z})+t_{i}^{\theta}\left[(k-4) \delta_{i}^{\theta}\right] \text { for } \theta \in\{\bar{H}, S\} .
\end{aligned}
$$

The first term stands for the labor income and the initial endowment in numeraire. The second terms denote tax revenues redistributed in a lump-sum fashion to residents, and the third term in $\mathbf{R}_{i}^{H}$ stands for the net return to capital invested in low-cost domestic firms (see eq. 3).

In order to describe total external benefits accruing to politically-connected managers, recall that $x_{i i}^{h, S}+x_{i j}^{h, S}$ gives the number of production workers employed by domestic high-cost firms. Total employment in each firm - including the manager - is equal to $\ell=1+x_{i i}^{h, S}+x_{i j}^{h, S}$ when $\theta=S$ whereas it is equal to 1 in domestic low-cost firms when $\theta=H .{ }^{20}$ Therefore, we obtain:

$$
\begin{aligned}
\mathbf{E}_{i}^{S} & =2 E\left(1+x_{i i}^{h, S}+x_{i j}^{h, S}\right) \\
\mathbf{E}_{i}^{H} & =2 E
\end{aligned}
$$

In the following, we present the tax outcome under laissez-faire (section 4.2.1) and bailout (section 4.2.2) policies.

\subsubsection{Tax equilibrium under laissez-faire policy}

We present the tax outcome when politically-connected managers exert a high effort and a low effort.

\section{Politically-connected managers exert a high effort}

Let us first assume that politically-connected managers exert a high effort in stage 0 . All firms being efficient and profitable, no public intervention is needed in stage 1 which is equivalent to a laissez-faire policy $(\theta=H)$. Hence, the first-order condition for each government at stage 2 writes:

$$
\frac{d W_{i}^{H}}{d t_{i}^{H}}=\underbrace{\delta_{i}^{H}(k-4)\left(\left|\varepsilon_{i}^{H}\right|-1\right)}_{+/-}+2+2 \underbrace{\frac{\partial \rho_{i}^{l, H}}{\partial t_{i}^{H}}}_{-}=0
$$

\footnotetext{
${ }^{20}$ Recall that there are no external benefits when $\theta \in \tilde{H}$ since domestic high-cost firms go bankrupt.
} 
The first term captures the taxation effect passing through tax revenues collected from foreign firms. For a given tax base, a marginal increase in $t_{i}^{H}$ raises tax revenues redistributed to residents. Nevertheless, this effect can be counterbalanced by a tax base effect capturing the capital outflow that results from a marginal increase in $t_{i}^{H}$. The total effect will be negative (resp. positive) if the tax base elasticity is higher (resp. lower) than 1 in absolute value. ${ }^{21}$ The second term gives the tax revenues collected from domestic firms. The last term captures the effect on the net return to capital invested in domestic firms. Evaluated at the location equilibrium, this net return to capital amounts to:

$$
\rho_{i}^{l, H}=r^{l, H}-\frac{1}{2}\left(t_{i}+t_{j}\right)+\frac{1}{4} \frac{\left(t_{i}-t_{j}\right)^{2}}{L \tau^{2}}
$$

with

$$
r^{l, H}=\frac{1}{4} L \frac{4 a(a-\tau)+\tau^{2}(k(k+2)+2)}{(k+1)^{2}} .
$$

Observe that both a higher average tax rate and a lower tax wedge between countries reduce the after-tax return on capital, as in Ottaviano and Van Ypersele (2005). Derivating (13) with respect to $t_{i}^{H}$, we verify that a unilateral rise in business taxation in country $i$ always reduces the net return to capital $\left(\partial \rho_{i}^{l, H} / \partial t_{i}^{H}<0\right)$.

Solving the first order condition for each government and crossing the reaction functions, we obtain:

$$
t_{i}^{H} \equiv t^{H}=L \tau^{2} \frac{k-2}{k+1} \forall i \in\{A, B\}
$$

\section{Politically-connected managers exert a low effort}

Let us now consider that politically-connected managers exert a low effort in stage 0 and governments choose the laissez-faire policy in stage 1. Given that all domestic firms exit the market, there is no income from domestic capital and government's objective function sums up to maximization of tax revenues from foreign firms. Therefore, at stage 2 , the government's first-order condition is:

$$
\frac{d W_{i}^{\bar{H}}}{d t_{i}^{\bar{H}}}=\underbrace{\delta_{i}^{\bar{H}}(k-4)\left(\left|\varepsilon_{i}^{\bar{H}}\right|-1\right)}_{+/-}=0
$$

Interestingly, the impact of a marginal rise in business taxation on tax revenues has a different magnitude than when $\theta=H$. Indeed, the capital outflow induced by a marginal rise in taxation (and thus, the tax base elasticity) is now lower because competition is relaxed by the liquidation of high-cost firms.

\footnotetext{
${ }^{21}$ We easily check that $\left|\varepsilon_{i}^{H}\right|>1$ at the equilibrium.
} 
After solving the first-order conditions, we obtain the following tax equilibrium:

$$
t_{i}^{\bar{H}} \equiv t^{\bar{H}}=L \tau^{2} \frac{k-4}{k-3} \quad \forall i \in\{A, B\}
$$

\subsubsection{Tax equilibrium under bailing-out decision}

We now turn to the tax outcome that occurs if governments decide to bailout firms in financial trouble at the previous stage of the game $(\theta=S)$. The first-order condition of each government at stage 2 is given by:

$$
\frac{d W_{i}^{S}}{d t_{i}^{S}}=\underbrace{\delta_{i}^{S}(k-4)\left(\left|\varepsilon_{i}^{S}\right|-1\right)}_{+/-}+\underbrace{2 \varphi E \frac{d \ell}{d t_{i}^{S}}}_{0}=0
$$

The first term of the first-order condition is qualitatively and quantitatively similar to the one arising when $\theta=H$, because location equilibria are identical. The second term describes a new relationship between tax policy and the total non-monetary benefits arising from the government's bailout. Interestingly, this incentive exists if and only if trade costs are higher than the threshold $\tau^{S}$ (trade regime 1). In this case, the total requirement in production labor of a rescued firm is equal to domestic sales only $\left(x_{i i}^{h, S}\right)$. By raising the business tax, the government induces a capital outflow that relaxes competition on the domestic market and increases the output per bailed-out firm. However, this relationship disappears when $\tau<\tau^{S}$, which corresponds to trade regime 2 under scrutiny here, because the sum of domestic sales and foreign ones $\left(x_{i i}^{h, S}+x_{i j}^{h, S}\right)$ does not depend on the spatial distribution of foreign firms.

Solving the first order condition for each government and crossing the reaction functions, we obtain:

$$
t_{i}^{S}=L \tau^{2} \frac{k-4}{k+1} \quad \forall i \in\{A, B\} \text { and } \tau<\tau^{S}
$$

\subsubsection{Tax comparison}

Let us now comment on the properties of the tax outcome. First, observe that equilibrium taxes are always increasing and convex in the level of trade costs : $d t^{\theta} / d \tau>0$ for all $\tau>0$ and $d^{2} t^{\theta} / d \tau^{2}>0$ for all $\theta$. Low trade costs weaken the pro-competitive effect and make footloose firms more responsive to business tax differences. This encourages governments to engage in a race to the bottom in taxation. This is a standard result in the tax competition literature assuming imperfectly integrated and imperfectly competitive economies (see, among others, Ottaviano and Van Ypersele 2005, Haufler and Wooton, 2010, Gaigné and Wooton, 2011). 
More importantly, the level of taxation at the equilibrium is also shaped by the effort made by politically-connected managers in stage 0 and the bailing out decision in stage 1. From (14), (15) and (16), we can rank the tax equilibria in the following way under trade regime 2 :

$$
t^{\bar{H}}>t^{H}>t^{S}>0 \quad \forall \tau<\tau^{S}
$$

Two mechanisms contribute to explain this ranking.

Recall that a given marginal increase in business taxation in a country leads to a lower capital outflow when $\theta=\bar{H}$ than when $\theta=H$ because competition is weakened by the exit of high-cost firms in the former case. Consequently, governments are more able to raise taxation. This effect contributes to explain why $t^{\bar{H}}>t^{H}$.

The sign of the difference between $t^{H}$ and $t^{S}$ is a priori not obvious. On the one hand, governments have an additional incentive to cut taxes when $\theta=H$ in order to raise the net return to capital invested in domestic firms (see eq. 12). On the other hand, domestic firms being an immobile tax base when $\theta=H$, governments are more incited to raise taxes. The fact that $t^{H}>t^{S}$ suggests that the latter effect dominates. Given the symmetry of the model, this result implies that for all $\tau<\tau^{S}$, governments collect more tax revenues under a laissez-faire policy than when they decide to bailout inefficient firms.

We are now equipped to analyze the bail-out decision of governments (stage 1). This decision being perfectly anticipated by politically-connected managers, we can determine their optimal effort (stage 0) and select the subgame Nash perfect equilibrium accordingly.

\section{$5 \quad$ Bailout decision and trade costs}

We first present the government's trade-off between the bailout and the laissez-faire policies (subsection 5.1). This section being dedicated to the effect of trade integration, we go beyond the benchmark case we considered so far (that is, trade regime 2) and describe how a shift from trade regime 1 to trade regime 2 impacts the equilibrium policy decision. Said differently, we analyze whether or not governments are more prone to adopt a bailout policy when trade integration is so deep that high-cost firms become exporters. Then, the last subsection (subsection 5.2) completes the analysis by discussing the impact of a gradual decline in trade costs within each trade regime. 


\subsection{The government's problem}

The choice between a laissez-faire policy and a bailout makes sense if and only if politicallyconnected managers exert a low effort. In such circumstances, the government selects the policy option maximizing the overall gain of residents including non-monetary benefits accruing to managers, by anticipating all the effects of its choice on the rest of the game (stages 2, 3 and 4). If this overall gain of residents $W_{i}^{\theta}$ is higher when $\theta=S$ than when $\theta=\bar{H}$, a bailout is preferred to the laissez-faire policy and politically-connected managers exert a low effort in order to enjoy a higher level of benefits (as E. $\ell>E$ ). Therefore, the decision path $S$ is the subgame perfect equilibrium of the game. Otherwise, the government adopts a laissez-faire policy and politically-connected managers exert a high effort. In that case, the decision path $H$ is the subgame perfect equilibrium.

Solving the government's problem therefore requires to evaluate the difference in the overall gain of residents between a bailout policy and a laissez-faire policy. ${ }^{22}$ If $\tilde{W}_{i}^{S}$ denotes the overall gain of residents that results from a bailout policy when $\tau \in\left(\tau^{S}, \tau^{H}\right)$, this difference amounts to:

$$
\begin{aligned}
& \tilde{W}_{i}^{S}-W_{i}^{\bar{H}}=\frac{1}{2}(k-4)\left(\tilde{t}_{i}^{S}-t_{i}^{\bar{H}}\right)+2 \varphi E \tilde{\ell} \text { under trade regime } 1 \\
& W_{i}^{S}-W_{i}^{\bar{H}}=\frac{1}{2}(k-4)\left(t_{i}^{S}-t_{i}^{\bar{H}}\right)+2 \varphi E \ell \text { under trade regime } 2
\end{aligned}
$$

with $\tilde{t}_{i}^{S}$ the equilibrium corporate tax and $\tilde{\ell}$ the equilibrium labor demand of a high-cost firm that occur under a bailout policy for all $\tau \in\left(\tau^{S}, \tau^{H}\right)$ (see next subsection).

Note that the outcome at stages 4,3 and 2 when $\theta=\bar{H}$ (and therefore $W_{i}^{\bar{H}}$ ) is the same across the two trade regimes as high-cost firms exit the market. Therefore, the trade regime influences the difference in the overall gain of residents only through the outcome in the presence of a bailout decision $\left(\tilde{W}_{i}^{S} \neq W_{i}^{S}\right)$. Moreover, whatever the trade regime, the difference in the overall gain of residents is decomposed in two terms.

The first term is the difference in tax revenues resulting from the two policy options, that depends on the tax differential between the two policy options. Therefore, it stands for the relative cost of a bailout policy as compared to a laissez-faire policy. In subsection 4.2.3, we showed that $t_{i}^{S}<t_{i}^{\bar{H}}$ under trade regime 2 . We extend the analysis to regime 1 in next subsection and show that the sign of $\tilde{t}_{i}^{S}-t_{i}^{\bar{H}}$ can be either positive or negative.

The second term captures the total political benefits arising from the amount of jobs saved thanks to the bailout. Through this term, our model rationalizes the too-big-to-fail motive for a bailout. This term is positive whatever the trade regime and proportional to

\footnotetext{
${ }^{22}$ This difference is evaluated at the equilibrium values of taxes and output, as governments perfectly anticipate the outcomes of stages 2,3 and 4 .
} 
the total labor force employed in domestic firms. Therefore, governments are more likely to rescue domestic manufacturing firms when the number of jobs involved is large.

Importantly, the level of trade integration influences the government's trade-off (18) in two respects. First, a discrete shift from trade regime 1 to trade regime 2 influences the outcome of a bailout decision and then, the relative costs and benefits of each policy option. We explore these effects in the next two subsections. Secondly, a gradual decline in trade costs within each trade regime affects the magnitude of the relative cost of each policy decision as well as the amount of total external benefit resulting from a bailout. This impact of gradual trade liberalization is analyzed in section 5.2.

\subsubsection{Bailout decision under trade regime 1}

Let us assume that trade costs lie within the range $\left(\tau^{S}, \tau^{H}\right)$, so that low-cost firms participate to bilateral trade whereas high-cost firms serve their domestic market only. In order to determine whether $\theta=S$ or $\theta=\bar{H}$ will be the equilibrium decision path, we first need to present the outcome at stages 4,3 and 2 of the game (hereafter $\tilde{p}_{i}^{S}, \tilde{\delta}^{S}, \tilde{t}^{S}$ ) in the presence of a bailout. In the short-run, equilibrium prices are given by:

$$
\tilde{p}_{i}^{S}=\frac{a+2+\tau \tilde{\delta}_{j}^{S}(k-4)}{k-1} \text { for all } \tau \in\left(\tau^{S}, \tau^{H}\right)
$$

In the long-run, the share of mobile firms set up in country $A$ for given tax policies writes:

$$
\tilde{\delta}_{A}^{S}=\frac{1}{2}-\frac{1}{2} \frac{k-1}{L \tau^{2}(k-4)}\left(t_{A}-t_{B}\right) \text { for all } \tau \in\left(\tau^{S}, \tau^{H}\right)
$$

Solving the tax competition game at stage 1, we obtain the following tax equilibrium level:

$$
\tilde{t}_{i}^{S}=L \tau^{2} \frac{k-4}{k-1}+\varphi \frac{\tau L}{k-1} E \quad \forall i \in\{A, B\} \text { for all } \tau \in\left(\tau^{S}, \tau^{H}\right)
$$

It is worth stressing that $\tilde{t}_{i}^{S}>t_{i}^{S}$. There are two reasons for that. Firstly, bailed-out firms being not competitive enough to export when $\tau \in\left(\tau^{S}, \tau^{H}\right)$, competition is relaxed for foreign firms which are less responsive to a given rise of taxation $\left(\left|d \delta_{A}^{S} / d t_{A}\right|>\left|d \tilde{\delta}_{A}^{S} / d t_{A}\right|\right)$. Secondly, the business tax in each country now depends positively on $E$. To understand this result, recall that the total non-monetary benefits accruing to politically-connected managers are proportional to the total output and jobs of the firms they manage. When trade regime 1 prevails, their total output boils down to output on their domestic market $\left(\tilde{x}_{i i}^{h, S}\right)$. This output $\tilde{x}_{i i}^{h, S}$ is obviously increasing in the domestic price level, but the latter goes down with the share of foreign firms located in the country (see eq. 19). This creates a new incentive to rise taxes as the resulting capital outflow relaxes competition on the 
domestic market, expands production from domestic firms and therefore increases total non-monetary benefits.

As a consequence, business taxes under trade regime 1 may become higher in the presence of a bailout than under a laissez-faire policy. As the following expression shows, this is more likely to happen when $E$ and/or $\varphi$ reach high values:

$$
\begin{aligned}
& \tilde{t}^{S}-t^{\bar{H}}=L \tau \frac{(k-3) \varphi E-2 \tau(k-4)}{(k-1)(k-3)} \gtrless 0 \\
& \text { when } E \gtrless \frac{2 \tau(k-4)}{\varphi(k-3)}=\tilde{E} \text { for all } \tau \in\left(\tau^{S}, \tau^{H}\right)
\end{aligned}
$$

Recalling that $t^{\bar{H}}>t^{S}$ when $\tau \in\left(0, \tau^{S}\right)$, the following proposition summarizes our results.

Proposition 2 Consider the tax competition subgame. For intermediary trade costs $\left(\tau \in\left(\tau^{S}, \tau^{H}\right)\right)$, corporate taxes are higher under bailout than under laissez-faire if and only if the amount of non-monetary benefits per job saved is high enough (i.e., $E>\tilde{E}$ ). For low trade costs $\left(\tau<\tau^{S}\right)$, corporate taxes are higher under a laissez-faire policy whatever the amount of non-monetary benefits per job saved.

Now let us analyze government's behavior at stage 1. Given the inequality (21), the first component of $\tilde{W}_{i}^{S}-W_{i}^{\bar{H}}$ (see eq. 18) can be viewed as the opportunity cost of the bailout when $E<\tilde{E}$, and the opportunity cost of the laissez-faire policy when $E>\tilde{E}$. As the second term is always positive, there is no trade trade-off for governments when $E>\tilde{E}$ : they always choose the bailout policy. This decision being perfectly anticipated by politically-connected managers, they choose a low effort. However, when $E<\tilde{E}$, governments are faced with a trade-off between the loss in tax revenues and the political benefits resulting from a bailout. Specifically:

$$
\tilde{W}_{i}^{S} \gtrless W_{i}^{\bar{H}} \text { if and only if } E \gtrless \hat{E}
$$

with

$$
\hat{E}=\frac{L \tau^{2}(k-4)^{2}}{\varphi(L((a+2)+(k-4) \tau)+(2(k-1)))(k-3)} \in(0 ; \tilde{E})
$$

The above inequality stipulates that political benefits from a bailout more than compensate for the loss in tax revenues for all $E \in(\hat{E}, \tilde{E})$. In this case, politically-connected managers anticipate a bailout in stage 1 and adopt a low effort. In contrast, governments will adopt a laissez-faire policy and politically-connected managers will choose a high effort when $E<\hat{E}$. To understand this result, one has to analyse the impact of $E$ on the relative cost of a bailout and its political benefits. On the one hand, a decline in $E$ reduces 
the relative cost of a bailout as the tax gap (21) is proportional to $E$. However, on the other hand, the reduction of per-job non-monetary benefit also reduces the total amount of political benefits accruing to managers. ${ }^{23}$ The former effect is predominant since we show that a bailout equilibrium is more likely to occur when the benefit per job saved is high.

\subsubsection{Bailout decision under trade regime 2}

Let us now assume that trade costs fall below the threshold $\tau^{S}$ so that high-cost firms start exporting as well. By replacing $t_{i}^{\bar{H}}, t_{i}^{S}, x_{i i}^{h, S}$ and $x_{i j}^{h, S}$ by their equilibrium values into (18), we get:

$$
W_{i}^{S} \gtrless W_{i}^{\bar{H}} \text { when } E \gtrless \frac{4 L \tau^{2}(k-4)^{2}}{\varphi(k-3)((2 a-2 k-\tau+6) L+2(k+1))}=\bar{E}
$$

Above a threshold $\bar{E}$, governments decide to bail-out domestic firms and politicallyconnected managers choose a low effort. Otherwise, the decision path $H$ describes the subgame perfect equilibrium. The intuition for this result is the following. A rise in the level of $E$ increases total political benefits, whereas it does not have any impact on the relative cost of a bailout as neither $t^{\bar{H}}$ nor $t^{S}$ depend on $E$. Thus, governments are more prone to bailout firms when $E$ rises because it increases total political benefits from the bailout without any impact on its relative cost.

Using the expressions of $\bar{E}$ and $\hat{E}$, it is now possible to analyze to what extent the equilibrium outcome depends on the level of trade costs. We easily check that $\hat{E}<\bar{E}$. (see Appendix). This leads us to formulate the following lemma.

Lemma 3 The policy choice of governments depends on non-monetary benefits of managers as follows:

- if $E<\hat{E}$, governments choose the laissez-faire policy and politically-connected managers exert a high effort whatever the trade regime;

- if $E \in(\hat{E}, \bar{E})$, governments bail out high-cost firms and politically-connected managers exert a low effort under trade regime 1, while the opposite result applies under trade regime 2;

\footnotetext{
${ }^{23}$ Given the symmetry of the model, equilibrium taxes are equalized across countries and the location equilibrium boils down to $\delta^{S}=1 / 2$. As a consequence, the individual output of a high-cost firm $\tilde{x}_{i i}^{h, S}$ is not influenced by the amount of external benefit per job saved. The latter only influences political benefits at the country level, as they are proportionnal to the number of firms run by politically-connected managers.
} 
- if $E>\bar{E}$, governments bail out high-cost firms and politically connected managers exert a low effort whatever the trade regime.

Thus, there exists a range of $E$ values making the government decision dependent on the trade regime. Indeed, when $E \in(\hat{E}, \bar{E})$, a bailout policy is observed at equilibrium if and only if high-cost firms are not competitive enough to export. The following proposition summarizes this result:

Proposition 4 Assume that $E \in(\hat{E}, \bar{E})$. If the economy shifts from trade regime 1 to trade regime 2, governments move away from a bailout policy to a laissez-faire policy.

The intuition for this result comes from the difference in the relative cost of a bailout as we move from one trade regime to the other. Indeed, $t^{\bar{H}}$ remains unchanged across trade regimes whereas $\tilde{t}^{S}>t^{S}$. Therefore, the relative cost of a bailout is lower when highcost firms only serve the domestic market (trade regime 1). That is the reason why the laissez-faire policy may become the optimal policy following a bilateral trade agreement that allows high-cost firms to start exporting.

\subsection{The effects of a gradual trade liberalization}

We now analyze, within each trade regime, the influence of a gradual decline in trade costs on governments' decision.

\subsubsection{Trade regime 1}

Let us first investigate the effect of a gradual trade liberalization over the interval $\left(\tau^{S}, \tau^{H}\right)$. Recall that when $E>\tilde{E}, \tilde{W}_{i}^{S}>W_{i}^{\bar{H}}$ holds for all $\tau \in\left(\tau^{S}, \tau^{\bar{H}}\right)$. Therefore, in what follows, we restrict our analysis to the most interesting case where $E<\tilde{E}$, in which a bailout may or may not be optimal (see proposition 1) because it engenders tax revenue losses $\left(\tilde{t}^{S}<t^{\bar{H}}\right)$. Under these circumstances, a gradual fall of trade costs gives rise to two opposite forces.

On the one hand, it is straightforward to check that $d\left(t^{\bar{H}}-\tilde{t}^{S}\right) / d \tau>0$ for all $E<\tilde{E}$ (see eq. (21)). Thus, the decline of trade costs over the interval $\left(\tau^{S}, \tau^{\bar{H}}\right)$ leads to a reduced wedge between $\tilde{t}^{S}$ and $t^{\bar{H}}$, which decreases the relative cost of a bailout in terms of tax revenues foregone. On the other hand, a fall in trade costs under trade regime 1 expands total output of low-cost firms, while it shrinks the output and employment of high-cost firms, which face fiercer competition on their domestic market (see eq. 23). 


$$
2 \tilde{\ell} \equiv 2\left(1+\tilde{x}_{i i}^{h, S}\right)=2\left(1+\frac{L}{4} \frac{2 a+\tau(k-4)+4}{k-1}\right) \forall \tau \in\left(\tau^{S}, \tau^{\bar{H}}\right)
$$

Therefore, the political benefits arising from a bailout decreases with total labor force employed in high-cost firms.

In order to figure out which one of these effects predominate, we differentiate $\hat{E}$ with respect to $\tau$ and obtain:

$$
\frac{d \hat{E}}{d \tau}=L \tau(k-4)^{2} \frac{(2(a+2)+\tau(k-4)) L+4(k-1)}{\varphi(k-3)((a+2+\tau(k-4)) L+(2 k-2))^{2}}
$$

which is positive and convex in $\tau$. Trade liberalization erodes the political benefits of a bailout by shrinking the number of jobs to save, but the magnitude of this effect is not large enough to compensate for the decrease in the relative cost of this policy. Therefore, a decline of trade costs over the range $\left(\tau^{S}, \tau^{H}\right)$ encourages governments to bailout high-cost firms.

\subsubsection{Trade regime 2}

When trade regime 2 prevails, the tax differential between a laissez-faire and a bailout policy is given by:

$$
t^{\bar{H}}-t^{S}=\frac{4 L(k-4)}{(k+1)(k-3)} \tau^{2} \quad \forall \tau \in\left(0, \tau^{S}\right)
$$

which is increasing in $\tau$. Then, a gradual decline in trade costs reduces the relative cost of a bailout as it does for trade regime 1.

To evaluate the impact of a gradual decline in $\tau$ on the political benefits, we derive the total labor force employed in the manufacturing sector of domestic firms at the subgame perfect equilibrium:

$$
2 \ell \equiv 2\left(1+x_{i i}^{h, S}+x_{i j}^{h, S}\right)=2\left(1+\frac{L}{2} \frac{2 a-2 k-\tau+6}{k+1}\right) \forall \tau \in\left(0, \tau^{S}\right)
$$

Clearly, gradual trade liberalization exerts a positive influence on the total labor force by expanding output of high-cost firms. The intuition is the following. Bilateral trade being facilitated, quantities sold by each firm decline on the domestic market while they increase on the export market. The latter effect dominates, so that total output is increasing as trade costs fall within the range $\left(0, \tau^{S}\right)$. Recall that the relationship goes in the opposite direction under trade regime 1 . Therefore, the impact of trade liberalization on the total political benefits arising from a bailout tightly depends on whether high-cost firms export or not. 
To summarize, the decline of trade costs has an unambiguous effect on the incentive for governments to bailout over the range $\left(0 ; \tau^{S}\right)$ : it leads to a decrease in the relative cost of the bailout policy and to an increase in its total political benefits. Therefore, it encourages governments to bailout high-cost firms and $d \bar{E} / d \tau>0$. As we also checked that $d \hat{E} / d \tau>0$, our results can be summarized by the following proposition.

Proposition 5 Gradual trade liberalization within each trade regime always encourages governments to adopt a bailout policy.

To provide a complete picture of the relationship between the level of trade costs and the incentives to bailout, Figure 2 simulates $\bar{E}$ (trade regime 2) and $\hat{E}$ (trade regime 1) with respect to $\tau$ for three different values of $\varphi$ (which captures the degree to which governments care about manufacturing jobs and the non-monetary benefits of politicallyconnected managers). ${ }^{24}$ Unsurprisingly, the higher $\varphi$, the lower the threshold values $\bar{E}$ and $\hat{E}$ above which governments decide to bail-out domestic firms. More importantly, we can visualize in Figure 2 the discontinuity in the incentive to bail-out that arises when the economy shifts from trade regime 1 to trade regime 2. Starting from high levels of trade costs such that trade regime 1 prevails, $\hat{E}$ decreases when trade costs fall. At $\tau^{S}$, represented by the vertical dash line, the threshold $E$ shifts upward because the relative cost of a bailout becomes larger. Below $\tau^{S}, \bar{E}$ decreases again with trade liberalization.

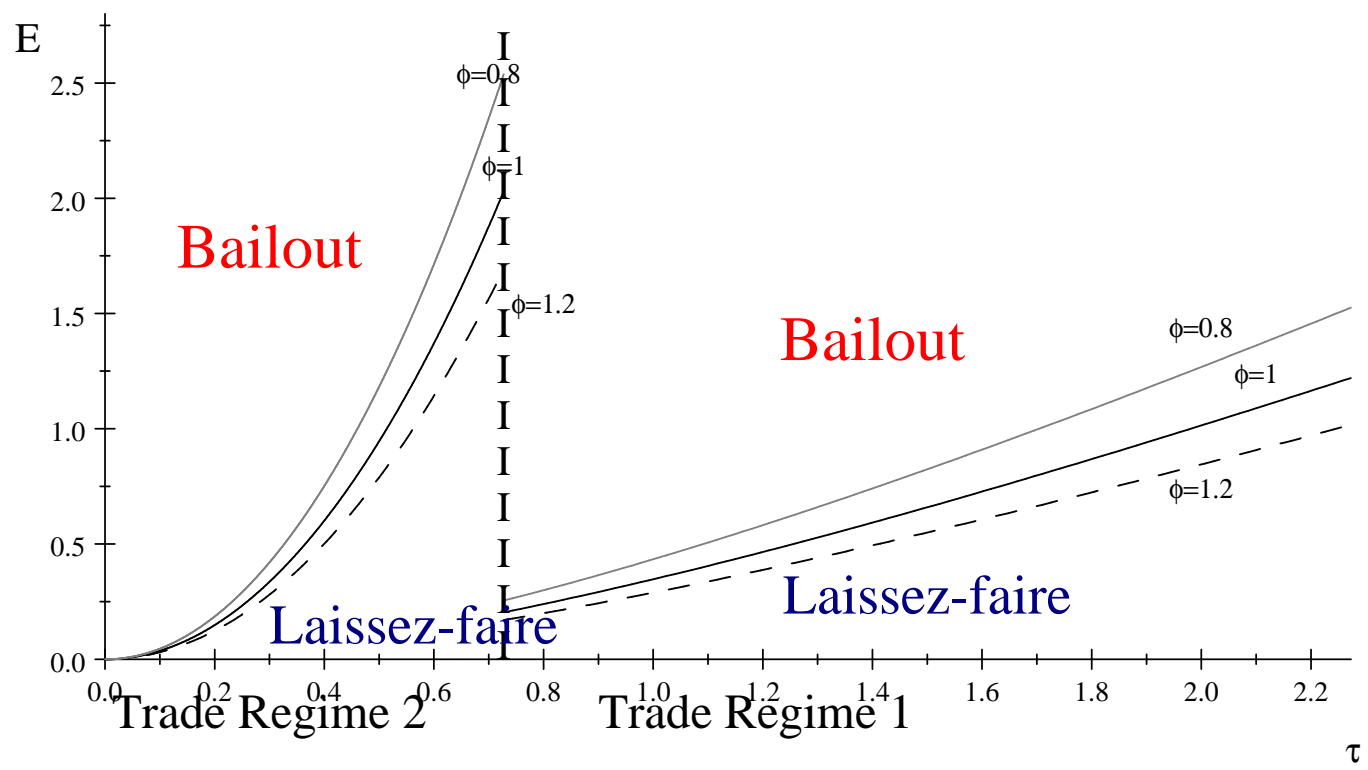

Figure 2: Bailout and Trade Regimes

\footnotetext{
${ }^{24}$ The numerical specification assumes: $k=20, a=25, L=100$.
} 


\section{Conclusion}

One might expect at first sight that governments are less prone to bailout inefficient firms in well integrated economies, for ideological or institutional reasons. However, we saw a resurgence of corporate bailouts in these countries. Our contribution provides a new explanation why such corporate bailouts occur in developped countries, by analysing how the fall in trade costs might incite governments to rescue firms rather than let them go bankrupt.

Using a 2-country model of generalized oligopoly with heterogenous firms and trade costs, we show that the government's attitude toward politically-connected firms depends on a trade-off between the relative cost of a bailout in terms of tax revenue losses and its potential political benefits. We assume that these political benefits are proportional to the total labor force in politically-connected firms, so that trade liberalization influences both the relative cost of a bailout and its political benefits. Importantly, this influence of trade liberalization differs depending on whether we focus on a continuous or a discrete decline in trade costs. If the fall in trade costs is large enough to allow high-cost firms to become exporters, governments might move away from a bailout policy to a laissez-faire policy (Proposition 1) because tax revenue losses that would be induced by a bailout decision rise suddenly. In contrast, a marginal decline in trade costs that does not change the export status of high cost firms always makes governments more prone to adopt a bailout decision.

Of course, our model is highly stylized. Still, we can replicate the above results under the alternative assumption that politically-connected firms are state-owned firms rather than private ones. We could also enrich the model by assuming that some domestic firms are run by market-oriented managers whereas others are run by politically-connected managers. This complicates the algebra without influencing the main results regarding the influence of trade liberalization on the bailout decision. Finally, it would be interesting to undertake an econometric analysis to figure out whether or not trade integration makes corporate bailouts more likely and, more crucially, if this impact differs when it comes to exporting firms as compared to non-exporting firms. We leave this investigation for future research. 


\section{Appendix}

\section{Wage and employment levels}

We make two specific assumptions regarding the labor market in order to determine wage and employment levels.

Firstly, we consider that the $T$ sector is always active in both countries so that labor mobility across sectors equalizes wages to unity in each country. Thus, we ensure that a single country cannot supply the world demand for the numéraire good, ${ }^{25}$ that is :

$$
L z_{i}^{\theta}>\frac{L}{2}
$$

with the individual consumption of numéraire

$$
\begin{aligned}
z_{i}^{\theta} & =\bar{z}+1+\frac{2}{L} T_{i}^{\theta}-p_{i}^{\theta}\left(a-p_{i}^{\theta}\right) \text { if } \theta \in\{\bar{H}, S\} \\
z_{i}^{\theta} & =\bar{z}+1+\frac{2}{L} T_{i}^{\theta}+\frac{4}{L} \rho_{i}^{l, \theta}-p_{i}^{\theta}\left(a-p_{i}^{\theta}\right) \text { if } \theta=H
\end{aligned}
$$

Secondly, we consider that in each country, that there is no labor shortage so that firms are always able to produce. Therefore, we assume that the national labor supply is never lower than national labor demand. At the location equilibrium, this condition implies:

$$
\frac{L}{2} \geqslant\left\{\begin{array}{c}
2+\frac{(k-4)}{2}+\frac{L}{2} z_{i}^{H} \text { when } \theta=H \\
2+\frac{(k-4)}{2}+2\left(x_{i i}^{h, S}+x_{i j}^{h, S}\right)+\frac{L}{2} z_{i}^{S} \text { when } \theta=S \\
\frac{(k-4)}{2}+\frac{L}{2} z_{i}^{\bar{H}} \text { when } \theta=\bar{H}
\end{array}\right.
$$

where the expressions on the right hand side stands for total labor demand (for both management and production jobs) under each market structures.

Replacing $z_{i}^{\theta}$ by their equilibrium values in each of the two inequalities, the conditions (A1) and (A2) implies that we consider the following intermediate level of individual endowment in numéraire:

$$
\bar{z} \in\left[z_{\min }^{\theta}, z_{\max }^{\theta}\right]
$$

where $z_{\min }^{\theta}$ and $z_{\max }^{\theta}$ are easily is deducted from, respectively, (A1) and (A2). Finally, we must ensure that $z_{\min }^{\theta}<z_{\max }^{\theta}$ for all $\theta \in\{S, H, \bar{H}\}$. Tedious but easy calculations leads to the conclusion that $z_{\max }^{H}$ is always higher than $z_{\min }^{H}$. Moreover, the assumption that $L>2 k$ is a sufficient condition to verify that $z_{\max }^{\bar{H}}>z_{\min }^{\bar{H}}$. Finally, the additional assumption that the demand parameter $a$ is lower than the threshold $a_{\max } \equiv(9 k-23) / 8$

\footnotetext{
${ }^{25}$ Note that this condition also garantees that the individual consumption in numéraire is positive.
} 
(which it itself higher than $a_{\text {min }}$ ) is a sufficient condition ensuring that $z_{\max }^{S}>z_{\min }^{S}$. We assume these necessary conditions hold. Therefore, there is always a range of endowment in numéraire such that wages are equal to unity (A1) and there is no labor shortage in each country (A2).

The intuition for this range of individual endowment in numéraire is the following. The individual endowment in numéraire $\bar{z}$ has to be high enough so that the world demand in numéraire cannot be served by only one country and therefore, all wages are equalized to unity thanks to labor mobility across sectors. Nevertheless, $\bar{z}$ - and thereby the size the $T$ sector - should not be too high so that, given the inelastic labor supply, there is no labor shortage for firms of each sector. While these assumptions seem to be constraining at a first sight, they prove the existence of parameter values (in terms of numéraire endowment) such that wages are equalized to one across all jobs and countries and there is no labor shortage. ${ }^{26}$

\section{- Comparison of threshold values $\hat{E}$ and $\bar{E}$}

Let $\hat{\Psi}=(L((a+2)+(k-4) \tau)+(2(k-1)))$ and $\bar{\Psi}=((2 a-2 k-\tau+6) L+2(k+1))$. Threshold values $\hat{E}$ and $\bar{E}$ can be rewritten as follows:

$$
\hat{E}=\frac{L \tau^{2}(k-4)^{2}}{\varphi(k-3) \hat{\Psi}} \text { and } \bar{E}=\frac{4 L \tau^{2}(k-4)^{2}}{\varphi(k-3) \bar{\Psi}}
$$

Thus, the difference writes,

$$
\bar{E}-\hat{E}=L \tau^{2}(k-4)^{2} \frac{(2 a+2 k-15 \tau+4 k \tau+2) L+(6 k-10)}{\varphi(k-3) \bar{\Psi} \hat{\Psi}}
$$

with $(2 a+2 k-15 \tau+4 k \tau+2)>0$ and $(6 k-10)>0$ for all $k>4$. Moreover, $\hat{\Psi}$ and $\bar{\Psi}$ are positive within the largest range of trade cost considered in this paper, that is $\tau \in\left\{0 ; \tau^{H}\right\}$. Therefore, we verify that $\bar{E}>\hat{E}$.

\section{References}

Alexeev M. and Y. Jang (2010). Trade liberalization, heterogeneous firms and the soft budget constraint, Journal of Comparative Economics 38(4), 449-460.

\footnotetext{
${ }^{26}$ Note also that the assumptions we make are less restrictive than if we considered that the labor market clears in each country. Clearly, some involuntarily unemployment occurs in our economy when there is excessive labor supply.
} 
Bortolotti B. and M. Faccio (2009). Government control of privatized firms, Review of Financial Studies 1, 1-33.

Cai H. and D. Treisman (2005). Does Competition for Capital Discipline Governments? Decentralization, Globalization, and Public Policy. American Economic Review 95(3), 817-830.

Chindooroy R., Muller P. and G. Notaro (2007). Company survival following rescue and restructuring State aid. European Journal of Law Economics 24,165-186.

Faccio M., Masulis R.W. and J. McConnell (2006). Political Connections and Corporate Bailouts, Journal of Finance 61, 2597-2635.

Gaigné C. and I. Wooton (2011). The gains from prefebenefitial tax regimes reconsidered, Regional Science and Urban Economics 41, 59-66.

Haufler A. and I. Wooton (2010). Competition for firms in an oligopolistic industry: The impact of economic integration, Journal of International Economics 80, 239-248.

Henderson, J.V. and J-F. Thisse (2004), Handbook of Regional and Urban Economics. Elsevier B.V.

Kornai J. (1979). Resource-constrained versus demand-constrained systems, Econometrica 47, 801-819.

Kornai J. (1986). The soft-budget constraint, Kyklos 39, 3-30.

Kornai J., Maskin E. and G. Roland (2003). Understanding the Soft Budget Constraint, Journal of Economic Literature, American Economic Association 41(4), 10951136 .

Kornai (2009). The soft budget constraint syndrome and the global financial crisis: Some warnings from an East European economist. Mimeo.

Melitz M. (2003). The Impact of Trade on Intra-Industry Reallocations and Aggregate Industry Productivity, Econometrica 71(6), 1695-1725.

Okubo T, Picard P. and J-F Thisse (2010). The spatial selection of heterogeneous firms. Journal of International Economics 82, 230-237.

Ottaviano G.I.P. and T. Van Ypersele (2005). Competition for firms in an oligopolistic industry: The impact of economic integration. Journal of International Economics 80 (2), 239-248.

Qian Y. and G. Roland (1998). Federalism and the Soft Budget Constraint. American Economic Review 88(5), 1143-62.

Robinson J. and R. Torvik (2009). A political economy theory of the soft budget constraint. European Economic Review 53(7), 786-798.

Rodrik, D. (1997). Has Globalization Gone Too Far ? Washington D.C : Institute for 
International Economics.

Schulze, G.G., et Ursprung, H.W. (1999). Globalisation of the Economy and the Nation State. The World Economy, 22(3), 295-352.

Segal I. (1998). Monopoly and soft budget constraint, Rand Journal of Economics 29(3), 596-609.

Shleifer A. and D. Treisman (2000). Without a Map: Political Tactics and Economic Reform in Russia. Cambridge, MA: MIT Press.

Slaughter M. (2008). An Auto Bailout Would Be Terrible for Free Trade. Does anyone really expect other countries to ignore our subsidies? Wall Street Journal, November 20.

Thisse J-F. (2010). Toward a unified theory of economic geography and urban economics, Golden Issue of Journal of Regional Science 50, 281-296. 